\title{
An EGFR inhibitor enhances the efficacy of SN38, an active metabolite of irinotecan, in SN38-refractory gastric carcinoma cells
}

\author{
M Yashiro*, I,2 , H Qiu' ${ }^{1,2,3}$, T Hasegawa', X Zhang',4, T Matsuzaki' and K Hirakawa' \\ 'Department of Surgical Oncology, Osaka City University Graduate School of Medicine, 1-4-3 Asahi-machi, Abeno-ku, Osaka 545-8585, Japan; \\ ${ }^{2}$ Oncology Institute of Geriatrics and Medical Science, Osaka City University Graduate School of Medicine, 1-4-3 Asahi-machi, Abeno-ku, Osaka \\ 545-8585, Japan; ${ }^{3}$ Oncology Center of Tongji Hospital, Tongji Medical College, Huazhong University of Science and Technology, Wuhan, PRC; \\ ${ }^{4}$ Department of Medical Oncology, Beijing Cancer Hospital, School of Oncology, Peking University, Beijing, PRC
}

BACKGROUND: Acquired drug resistance to irinotecan is one of the significant obstacles in the treatment of advanced gastric cancer. This study was performed to clarify the effect of epidermal growth factor receptor (EGFR) inhibitors in combination with SN38, an active metabolite of irinotecan, on the proliferation of irinotecan-refractory gastric cancer.

METHODS: Two irinotecan-resistant gastric cancer cell lines, OCUM-2M/SN38 and OCUM-8/SN38 were, respectively, established by stepwise exposure to SN38 from the parent gastric cancer cell lines OCUM-2M and OCUM-8. The combination effects of two EGFR inhibitors, gefitinib and lapatinib, with SN38 on proliferation, apoptosis, and cell cycle on gastric cancer cells were examined.

RESULTS: Gefitinib or lapatinib showed synergistic anti-tumour effects against OCUM-2M/SN38 and OCUM-8/SN38 cells when used in combination with SN38, but not against OCUM-2M or OCUM-8 cells. SN38 increased the expression of EGFR and HER2 in OCUM-2M/SN38 and OCUM-8/SN38 cells. The combination of an EGFR inhibitor and SN38 significantly increased the levels of apoptosis-related molecules, caspase-6, p53, and DAPK-2, and resulted in the induction of apoptosis of irinotecan-resistant cells. The EGFR inhibitors increased the S-phase and decreased the UGTIAI and ABCG expression in irinotecan-resistant cells. The SN38 plus Lapatinib group more effectively suppressed in vivo tumour growth by OCUM-2M/SN38 cells than either alone group. CONCLUSION: The combination treatment with an EGFR inhibitor and irinotecan might produce synergistic anti-tumour effects for irinotecan-refractory gastric cancer cells. The regulation of SN38 metabolism-related genes and cell cycle by EGFR inhibitors might be responsible for the synergism.

British Journal of Cancer (201 I) I 05, 1522- 1532. doi: I0.1038/bjc.201 I.397 www.bjcancer.com

Published online 13 October 2011

(c) 201। Cancer Research UK

Keywords: gastric cancer; chemoresistance; irinotecan; EGFR inhibitor; combination therapy

Gastric cancer remains a major health threat worldwide, and most patients with the advanced-stage disease require chemotherapy. Camptothecin (CPT), a DNA topoisomerase I inhibitor, blocks the DNA religation of topoisomerase cleavage complexes (Pommier et al, 1998), and is one of the effective anti-cancer drugs used in the chemotherapy of many types of solid tumours (Farhat, 2007; Segal and Saltz, 2009). Irinotecan hydrochloride (CPT-11) is currently clinically used as one of the preferred choices in monotherapy or combination therapy in advanced gastric cancer (Bugat, 2003; Arnold et al, 2006; Farhat, 2007). Also, irinotecan-based chemotherapy is recommended as a second-line treatment for gastric cancer patients according to the guideline of the National Comprehensive Cancer Network (1998). Although the development of drug resistance to CPT-11 is one of the greatest obstacles, a few effective therapies to combat chemoresistance to CPT-11 are currently available (Xu and Villalona-Calero, 2002).

With respect to advanced gastric cancer, a combination therapy using a molecular targeting compound and a chemotherapeutic inhibitor might achieve a better response rate not only for

*Correspondence: Dr M Yashiro; E-mail: m9312510@med.osaka-cu.ac.jp Received 17 August 2011; revised 12 September 2011; accepted 12 September 201 I; published online 13 October 2011 chemonative carcinomas but also for chemorefractory carcinomas, compared to therapy with a chemotherapeutic inhibitor alone. However, the effects of such a combination in patients with advanced gastric cancer remain to be clarified.

The human epidermal receptor (HER) family consists of four closely related transmembrane receptors: the HER1/epidermal growth factor receptor (EGFR), HER2, HER3, and HER4. Epidermal growth factor signals participate in the regulation of a variety of cell functions, including cell differentiation, proliferation, apoptosis, migration, and angiogenesis (Kishida et al, 2005; Kim et al, 2008). Epidermal growth factor receptor is highly expressed in approximately one-third of advanced-stage gastric cancers (Nicholson et al, 2001; Rojo et al, 2006; Galizia et al, 2007; Liakakos et al, 2008), and the activation of EFGR may be involved in chemoresistance in solid tumours (Ciardiello and Tortora, 2001). Recently, small molecules acting as tyrosine kinase inhibitors (TKIs) have begun to emerge as potential therapeutics for use in combination with cytostatic drugs in various types of carcinomas. Two studies have reported that an EGFR inhibitor in combination with cytostatic drugs achieved a better response rate for chemorefractory colorectal carcinomas than the cytostatic drugs alone (Cunningham et al, 2004; Saltz et al, 2004). Although preliminary data indicate that gefitinib monotherapy has limited efficacy for the treatment of gastric carcinoma (Yokoyama et al, 2006), 
preclinical data have shown the benefit of TKIs, including gefitinib, especially in combination with conventional cytostatic therapy (Becker et al, 2006a). A phase II study showed that gefitinib alone did not show clinical benefit in gastric carcinomas (Knight et al, 2004), while there was a significant correlation between increased exposure to gefitinib and enhanced apoptosis (Rojo et al, 2006). In certain gastric cancer cell lines, SN38, an active metabolite of irinotecan, has been shown to induce the tyrosine phosphorylation of EGFR (Kishida et al, 2005), which are considered to be involved in the development of drug resistance to irinotecan. Therefore, the blockage of the EGFR signalling in combination with SN38 may contribute to anti-tumour effects against irinotecan-refractory gastric cancer.

In the present study, we evaluated whether the combination of SN38 with either gefitinib or lapatinib might be useful for the treatment of chemoresistant gastric cancer cells, and if so, via what mechanism. Our results showed that both these EGFR inhibitors reversed the resistance to irinotecan and enhanced the antitumour efficacy of SN38.

\section{MATERIALS AND METHODS}

\section{Chemicals}

A stock solution of small-synthetic molecules, gefitinib (a TKI against EGFR; Sigma, St Louis, MO, USA) and lapatinib (GW572016; a TKI against EGFR and HER2; Toronto Research Chemicals, ON, Canada), at $37 \mathrm{~mm}$ in dimethyl sulfoxide was stored at $-20{ }^{\circ} \mathrm{C}$, and diluted to the desired concentration by Dulbecco's modified Eagle's medium (Nikken Biomedical Laboratory, Kyoto, Japan) before the experiment was done.

\section{Chemotherapeutic agents}

Five chemotherapeutic drugs, irinotecan (SN38; Yakult, Tokyo, Japan), oxaliplatin (OXA; Yakult), 5-fluorouracil (5-FU; Kyowa Hakko, Tokyo, Japan), paclitaxel (PTX; Bristol-Myers, Wallingford, CT, USA), and gemcitabine (GEM; Eli Lilly, Kobe, Japan), were used in this study. All were used according to the protocol provided by the manufacture. SN38 (Yakult) was dissolved by $1 \mathrm{~mm}$ natrium hydroxydatum at the concentration of $1 \mathrm{M}$, stored at $-20^{\circ} \mathrm{C}$, and diluted to the desired concentration by medium at the $\mathrm{pH}$ from 7.0 to 7.4 .

\section{Cell lines}

OCUM-2M (Yashiro et al, 1995) and OCUM-8 (Takemura et al, 2004) were derived from diffuse-type human gastric tumours. A panel of human gastric cancer cell lines including both the parental and chemoresistant sublines was used. Ten gastric cancer cell sublines resistant to SN38, OXA, 5-FU, PTX, and GEM were, respectively, established from two parent scirrhous gastric cancer cell lines, OCUM-2M and OCUM-8, by stepwise exposure to each of the five anti-cancer drugs. The drug-resistant gastric cancer cell lines from OCUM-2M were named OCUM-2M/SN38, OCUM-2M/ OXA, OCUM-2M/5-FU, OCUM-2M/PTX, and OCUM-2M/GEM, respectively (Zhang et al, 2010). In addition, drug-resistant gastric cancer cell lines were established from OCUM-8 and designated OCUM-8/SN38, OCUM-8/OXA, OCUM-8/5-FU, OCUM-8/PTX, and OCUM-8/GEM, respectively.

\section{Proliferation assay}

The effect of chemotherapeutic drugs with or without the smallsynthetic molecules (gefitinib or lapatinib) on the proliferation of gastric cancer cells was determined by 3-(4,5-dimethylthiazol-2yl)-2, 5-diphenyltetrazoliumbromide (MTT; Sigma) assay. Cancer cells were seeded into two 96 -well plates at a concentration of 5000 cells per well with culture medium exposed to each chemotherapeutic drug at different concentrations and/or gefitinib $(2.5 \mu \mathrm{M})$ or lapatinib $(200 \mathrm{nM})$. After incubation for $72 \mathrm{~h}$, MTT was added into each well. The formazan product of MTT was measured as absorbance at $570 \mathrm{~nm}$ using a microtiter plate reader (PM2004, Wako, Osaka, Japan). The percentage of cell viability was determined as the ratio of the absorbance of the sample $v s$ the control. Three independent experiments were performed. The $\mathrm{IC}_{50}$ of chemotherapeutic drug was determined as each chemotherapeutic drug concentration showing $50 \%$ cell growth inhibition as compared with the control cell growth. Six replicate wells were used for each drug concentration and the testing was carried out independently three times. The potential synergy between the small-molecule kinase inhibitors and 5-FU was evaluated, using the multiple drug-effect analysis with CalcuSyn software (Version 2.0, Biosoft, Cambridge, UK) including the combination index (CI) method of Chou and Talalay (1984), in which the $\log 10 \mathrm{CI}$ indicates synergism: $(\log \mathrm{CI}<0)$, additive effect: $(\log \mathrm{CI}=0)$ or antagonism: $(\log \mathrm{CI}>0)$.

\section{Apoptosis assay}

Apoptosis in response to $\mathrm{SN} 38$ in the presence or absence of gefitinib was examined using flow cytometry by staining the cells with annexin V-FITC and propidium iodide (Medical and Biological Laboratories, Nagoya, Japan) labelling. Cells were inoculated in $100-\mathrm{mm}$ dishes at a concentration of $1.0 \times 10^{5}$ cells ml $^{-1}$ with SN38 (at concentration of $\mathrm{IC}_{50}$ ) and/or the gefitinib $(2.5 \mu \mathrm{M})$. After incubation for $72 \mathrm{~h}$, cells were harvested and stained with annexin V-FITC and propidium iodide, and analysed by FACScan flow cytometry (Becton Dickinson, Mountain View, CA, USA). Three independent experiments were performed.

\section{Cell-cycle test}

The cell-cycle phase distribution was evaluated using flow cytometry. Cancer cells $\left(2 \times 10^{4}\right.$ cells $)$ were seeded into a 100 -mm dish with vehicle or EGFR TKI for cell-cycle test. After incubation for $72 \mathrm{~h}$, the cells were harvested and managed according to the instructions of the Cycle TEST PLUS DNA reagent kit protocol (Becton Dickinson), then incubated with ribonuclease A for $10 \mathrm{~min}$ at room temperature, and with propidium iodide for $30 \mathrm{~min}$ in the dark on ice. The sub-G0/G1, $\mathrm{S}$, and G2/M-phase fractions of $2 \times 10^{4}$ cells were determined by flow cytometry using a FACScaliber (Becton Dickinson). The results were analysed using the Modofit software program (Becton Dickinson).

\section{Reverse transcription - PCR}

The total cellular RNA was extracted using Trizol reagent (Invitrogen, Carlsbad, CA, USA) according to the manufacturer's protocol. After the genomic DNA was removed by DNAse, cDNA was prepared from $2 \mu \mathrm{g}$ of RNA with Maloney mouse leukaemia virus reverse transcriptase (Invitrogen) using random primers (Invitrogen). To investigate the influence of SN38 on the expression of EGFR and HER2 in gastric cells, exponential growing cells without or with $\mathrm{SN} 38$ at $\mathrm{IC}_{50}$, respectively, were seeded into $100-\mathrm{mm}$ dishes at a concentration of $3.0 \times 10^{5} \mathrm{cells} \mathrm{ml}^{-1}$, and incubated for further $24 \mathrm{~h}$ before cell harvest. For the examination of expression at the mRNA level of apoptosis-related genes, including Capasase-6, p53, death-associated protein kinase-1 (DAPK-1), DAPK-2, and DAPK-3, and SN38 metabolism-related genes including UGT1A1 and ABCG2, cancer cells were incubated for $24 \mathrm{~h}$ in the presence or absence of lapatinib or gefitinib. Quantitative real-time RT-PCR was done on the ABI Prism 7000 (Applied Biosystems, Foster City, CA, USA) using the commercially available gene expression assay for EGFR 
(Hs01076091), HER2 (Hs01001580), Capasase-6 (Hs00154250), p53 (Hs01034249), DAPK-1 (Hs00234489), DAPK-2 (Hs00204888), DAPK-3 (Hs00154676), UGT1A1 (Hs01053796), and ABCG2 (Hs02511055). PCR was performed at $95^{\circ} \mathrm{C}$ for $15 \mathrm{~s}$ and $60^{\circ} \mathrm{C}$ for $60 \mathrm{~s}$ for 40 cycles. As internal standard to normalise mRNA levels for differences in sample concentration and loading, amplification of glyceraldehyde-3-phosphate dehydrogenase was used. The threshold cycle $\left(C_{\mathrm{t}}\right)$ values were used for calculation of the relative expression ratios between control and treated cells using the formula described by Pfaffl (2001). All quantitative PCR reactions were done in triplicate.

\section{Western blot analysis}

Cell lysates were collected after different treatments. After the protein concentration of each sample was adjusted, electrophoresis was carried out using $10 \%$ Tris/Gly gels (Invitrogen Life Technologies, Inc., Gaithersburg, MD, USA). The protein bands obtained were transferred to an Immobilon-P Transfer membrane (Amersham, Aylesbury, UK). The membrane was kept in PBS-T (10 mM PBS and $0.05 \%$ Tween 20 ) supplemented with $5 \%$ bovine albumin (Sigma) at room temperature for $1 \mathrm{~h}$. Then, the membrane was placed in PBS-T solution containing each primary antibody: EGFR (Millipore, Billerica, MA, USA), ErbB2 (Dako, Cambridge, UK), cleaved caspase-6 (Assay Biotechnology, Sunnyvale, CA, USA), and p53 (Dako), and DAPK-2, and allowed to react at room temperature for $2 \mathrm{~h}$. The levels of specific proteins in each lysate were detected by enhanced chemiluminescence using ECL plus (Amersham) followed by autoradiography.

\section{Animal models}

BALB/c nude mice (Clea Japan, Shizuoka, Japan) were used. All experiments with nude mice were performed in accordance with the animal experiments guidelines approved by Osaka City University Ethical Committee. Xenografts were established by injecting $1 \times 10^{7}$ OCUM-2M/SN38 cells into the flanks of mice at 4 weeks of age. Mean tumour size was observed to be $60 \mathrm{~mm}^{2}$ at 10 days after inoculation. Accordingly, $10 \mathrm{mg} \mathrm{kg}^{-1}$ per day of SN38, and/or $30 \mathrm{mg} \mathrm{kg}^{-1}$ per day of Lapatinib was administered for 5 days per week for 3 weeks, except in control. SN38 was intraperitoneally injected, and Lapatinib was administered orally. Tumour size $(S)$ was determined at each time point by measuring length $(l)$ and width $(w)$, then calculating the volume $(V=l w)$. Medication-defined groups were Vehicle (control group; $n=8$ ), Lapatinib ( $30 \mathrm{mg} \mathrm{kg}^{-1}$ per day; $\left.n=8\right)$, SN38 $\left(10 \mathrm{mg} \mathrm{kg}^{-1}\right.$ per day; $n=8)$, Lapatinib combined with $\operatorname{SN} 38(n=8)$. The synergistic effect was determined when the value by the combination of lapatinib with SN38 was less than the expected value, as previously reported (Marth et al, 1986): The expected value $\left(\mathrm{mm}^{2}\right)$ of the combined effects $=$ the effects of SN38 $\left(\mathrm{mm}^{2}\right) \times$ the effects of lapatinib $\left(\mathrm{mm}^{2}\right) /$ vehicle control $\left(\mathrm{mm}^{2}\right)$.

\section{Statistical analysis}

The quantitative ratios of different groups were compared using Student's $t$-test. Probability values of $P<0.05$ were regarded as statistically significant. All statistical tests were two sided.

\section{RESULTS}

Combination effects of an EGFR inhibitor and anti-cancer drugs on the proliferation of gastric cancer cells

Figure 1A shows the anti-proliferative effect of each of the five anti-cancer drugs, SN38, OXA, 5-FU, PTX, or GEM, in combination with gefitinib in OCUM-2M cells and the respective daughter cell lines resistant to each of the five chemotherapeutic drugs. Gefitinib increased the anti-proliferation effect of SN38 in OCUM$2 \mathrm{M} / \mathrm{SN} 38$ cells, but not in the other cell lines. With respect to the effects on OCUM-8/SN38 and the respective daughter chemoresistant cell lines, gefitinib increased the anti-proliferation effect of SN38 in OCUM-8/SN38 cells, but not in the other cell lines (data not shown).

Figure 1B shows the cell growth inhibition curve of SN38 in the presence or absence of $2.5 \mu \mathrm{M}$ gefitinib or $200 \mathrm{nM}$ lapatinib in OCUM-2M, OCUM-2M/SN38, OCUM-8, and OCUM-8/SN38 cells. The $\mathrm{IC}_{50}$ value (the drug concentration needed for $50 \%$ growth reduction on the survival curve) of SN38-resistant cell lines and their parent cell lines to SN38 was summarised in Table 1 . The $\mathrm{IC}_{50}$ value for SN38-resistant sublines, OCUM-2M/SN38 (304 nM) and OCUM-8/SN38 (10.5 nM), was higher than that of parent cell lines, OCUM-2M (6.4 nM) and OCUM-8 (2.6 nM). The resistance index (RI) was calculated as the ratio of the $\mathrm{IC}_{50}$ of the drug-resistant cell line to the $\mathrm{IC}_{50}$ of parent cell line. The RI values of OCUM-2M/ SN38 and OCUM-8/SN38 cells against SN38 were 47.5 and 4.0, respectively. The RI values of OCUM-2M/SN38 and OCUM-8/SN38 cells against SN38 were both $>3.0$, confirming that each subline was resistant to SN38.

The $\mathrm{IC}_{50}$ value for OCUM-2M/SN38 was decreased by co-exposure to SN38 and gefitinib ( $50 \mathrm{nM})$, and co-exposure to SN38 and lapatinib (78 nM), in comparison with SN38 alone (304 nM). Taken together, the $\mathrm{IC}_{50}$ values for OCUM-8/SN38 cells was decreased by co-exposure to SN38 and gefitinib (1.6 nM), and coexposure to SN38 and lapatinib (1.3 nM), in comparison with SN38 alone $(10.5 \mathrm{nM})$. On the other hand, neither EGFR inhibitor (gefitinib at $2.5 \mu \mathrm{M}$ or lapatinib at $200 \mathrm{~nm}$ ) significantly suppressed the proliferation of any of the cell lines in this study when used alone.

\section{Synergistic effects of EGFR inhibitors on the anti-proliferative efficiency of SN38}

Figure 2A shows the effects of the EGFR inhibitors on the antiproliferative efficiency of SN38. In OCUM-2M cells, the proliferation rates of gefitinib, SN38 (5 nM), and gefitinib with SN38 were $93 \%, 32.6 \%$, and $24.8 \%$, respectively. In OCUM-2M/SN38 cells, the cell growth rates after exposure to gefitinib, SN38 (240 nM), or gefitinib plus SN38 were, respectively, $97 \%, 74 \%$, and $34 \%$, from which it could be concluded that gefitinib clearly inhibited the cell growth of OCUM-2M/SN38 when administered in combination with SN38. In OCUM-8 cells, the proliferation rates after administration of gefitinib, SN38 (5 nM), or gefitinib with SN38 were, respectively, $93 \%, 32 \%$, and $29 \%$. In OCUM-8/SN38 cells, the growth rates following administration of gefitinib, SN38 (240 nM), and gefitinib plus SN38 were, respectively, $108 \%, 59 \%$, and $36 \%$, from which it could be concluded that the combination treatment clearly inhibited the growth of OCUM-2M/SN38 cells. The expected value of the combined effects (\%) was defined as: effects of SN38 alone/control $\times$ effects of gefitinib alone/control $\times 100 \%$. The combination effects of gefitinib with SN38 were synergistic, in both the SN38-resistant cell lines and OCUM-2M because the proliferation rate associated with the combination of SN38 and gefitinib $(24.8 \%, 34 \%, 29 \%$, and $36 \%)$ was less than the expected value $(30.3 \%, 71.8 \%, 30 \%$, and $63.7 \%)$ in OCUM-2M, OCUM-2M/ SN38, OCUM-12, and OCUM-12/SN38 cells, respectively. The proliferation of SN38-resistant cells exposed to the combination of gefitinib plus SN38 was lower than expected (Figure 2A). Figure 2B shows the plotted combination results of SN38 with gefitinib or lapatinib at various concentrations. When data were analysed by the CalcuSyn software program, the effects of these combinations of EGFR inhibitors with SN38 were synergistic $(\log \mathrm{CI}<0)$ in both the SN38-resistant cell lines OCUM-2M/SN38 and OCUM-8/SN38. In contrast, antagonistic effect $(\log \mathrm{CI}>0)$ was found at $>128 \mathrm{nM}$ SN38 and 16 nM SN38 with the combination in the parent cell lines, OCUM-2M and OCUM-8, respectively. 
A
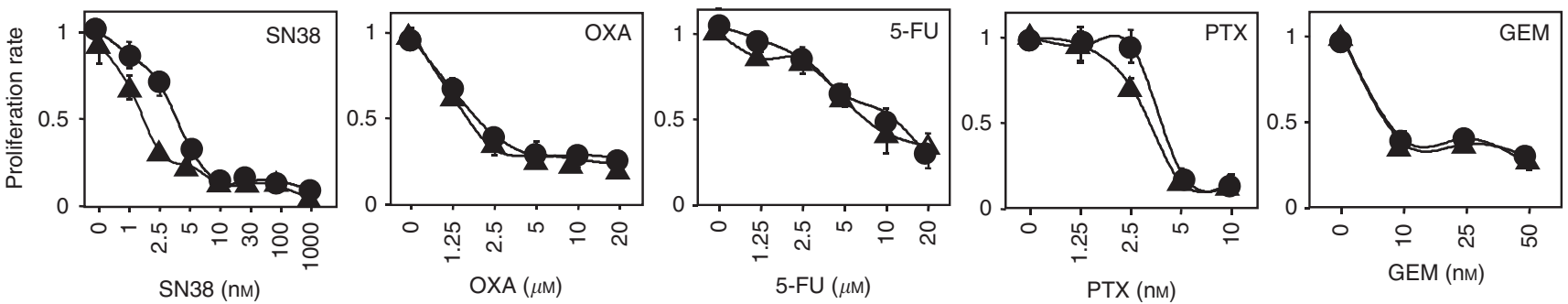

Chemoresistant cell lines
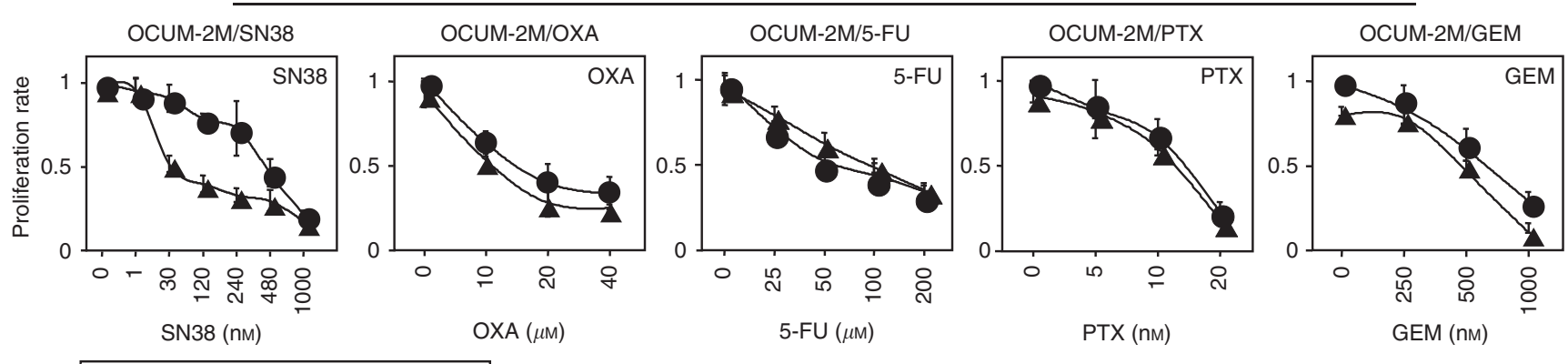

: Control, $\quad \mathbf{\Delta}$ : With gefitinib $(2.5 \mu \mathrm{m})$

B
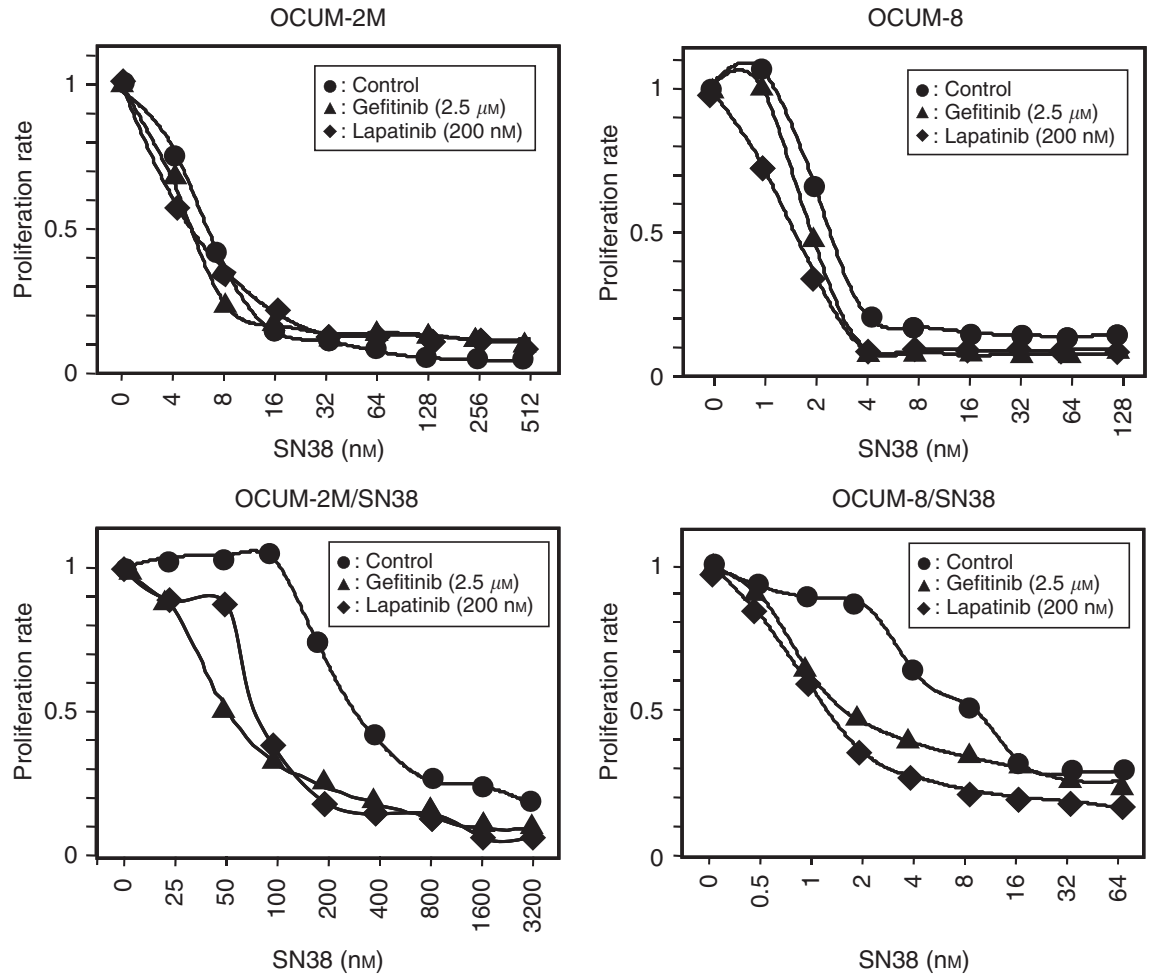

Figure I Growth-inhibitory effects of gefitinib or lapatinib with SN38 in gastric cancer cell lines. (A) A human gastric cancer cell line, OCUM-2M, and chemoresistant sublines were exposed to each chemotherapeutic drug at different concentrations in the absence $(\boldsymbol{O})$ or presence of gefitinib $(\mathbf{\Lambda})$. Gefitinib increased the anti-proliferation effect of SN38 in SN38-resistant cell line, OCUM-2M/SN38, but not other cell lines. (B) Gefitinib and lapatinib decreased the $I_{50}$ values of SN38-resistant cell lines, OCUM-2M/SN38 and OCUM-8/SN3, but not that of parent cell lines, OCUM-2M and OCUM-8. Gastric cancer cells were exposed to SN38 at various concentrations in the absence $(\mathbf{O})$ or presence of gefitinib $(\mathbf{\Lambda})$ or lapatinib $(\bullet)$.

\section{Effects of SN38 on EGFR or HER2 gene expression in gastric cancer cells}

In OCUM-2M/SN38 and OCUM-8/SN38 cells, the expression levels of EGFR and HER2 were higher than those in the parent OCUM-2M and OCUM-8 cells. The expression levels of EGFR and HER2 was significantly increased by SN38 in OCUM-2M/SN38 and OCUM-8/ SN38 cells, but not in OCUM-2M and OCUM-8 cells (Figure 3A). Taken together, the protein levels of EGFR and HER2 were increased by SN38 in OCUM-2M/SN38 and OCUM-8/SN38 cells (Figure 3B). 


\section{Effect of SN38 on the apoptosis of cancer cells in the} presence or absence of EGFR inhibitors

Figure $4 \mathrm{~A}$ shows the rates of apoptosis induced by SN38, gefitinib $(2.5 \mu \mathrm{M})$, or both. The apoptosis rates of the control group and the

Table I IC 50 values of SN38-resistant cell lines and their parent cell lines to $\mathrm{SN} 38$

\begin{tabular}{lccc}
\hline & \multicolumn{3}{c}{ IC 5 values for SN38 } \\
\cline { 2 - 4 } Cell line & SN38 alone & $\begin{array}{c}\text { SN38 with } \\
\text { gefitinib } \\
\mathbf{( 2 . 5} \boldsymbol{\mu} \text { M) }\end{array}$ & $\begin{array}{c}\text { SN38 with } \\
\text { lapatinib } \\
(\mathbf{2 0 0} \mathbf{n M})\end{array}$ \\
\hline OCUM-2M & $6.4 \mathrm{nM}$ & $5.4 \mathrm{nM}$ & $5.4 \mathrm{nM}$ \\
OCUM-2M/SN38 & $304 \mathrm{nM}$ & $50 \mathrm{nM}$ & $78 \mathrm{nM}$ \\
OCUM-8 & $2.6 \mathrm{nM}$ & $1.9 \mathrm{nM}$ & $1.6 \mathrm{nM}$ \\
OCUM-8/SN38 & $10.5 \mathrm{nM}$ & $1.6 \mathrm{nM}$ & $1.3 \mathrm{nM}$ \\
\hline
\end{tabular}

A

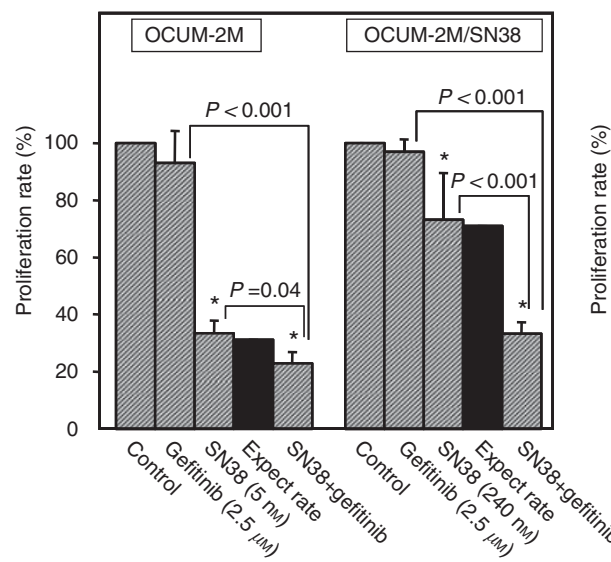

gefitinib $(2.5 \mu \mathrm{M})$ monotherapy group were $4.2 \%$ and $3.5 \%$ in OCUM-2M cells, and $3.2 \%$ and $5.3 \%$ in OCUM-2M/SN38 cells, respectively. The apoptosis rates of the control group and gefitinib monotherapy group were $3.3 \%$ and $2.1 \%$ in OCUM- 8 cells, and $3.8 \%$ and $3.2 \%$ in OCUM-8/SN38 cells, respectively. No significant difference in apoptosis rates was observed between the control group and gefitinib group in any of the gastric cancer cell lines. When OCUM-2M was co-exposed to SN38 (5 nM) and gefitinib $(2.5 \mu \mathrm{M})$, the apoptosis rate was significantly $(P<0.01)$ increased to $22.4 \%$, compared with that $(14.8 \%)$ after exposure to SN38 alone. In OCUM-2M/SN38 cells, the apoptosis rates achieved by the combination of SN38 $(240 \mathrm{nM})$ and gefitinib was significantly $(P<0.001)$ increased to $35.1 \%$, compared with the apoptosis rate (15.9\%) by SN38 (240 nM) alone. In OCUM-8 cells, the combination of SN38 $(2 \mathrm{nM})$ and gefitinib $(2.5 \mu \mathrm{M})$ induced apoptosis at a rate of $6.4 \%$ in comparison to the rate of $5.3 \%$ induced by SN38 ( $2 \mathrm{nM}$ ) alone. In OCUM-8/SN38 cells, gefitinib plus SN38 (7.5 nM) achieved a $13.8 \%$ rate of apoptosis, which was significantly higher than the rate of $4.1 \%$ induced by SN38 $(7.5 \mathrm{nM})$ alone $(P<0.001)$. In contrast, there was no significant difference in the rates of

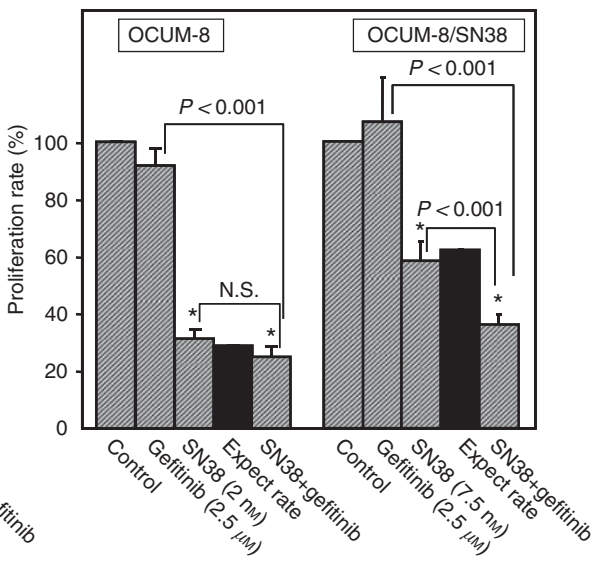

B

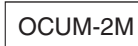

Gefitinib

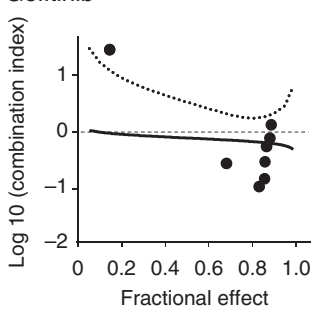

Fractional effect

Lapatinib

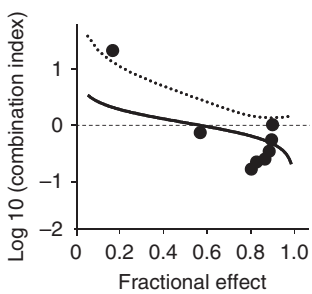

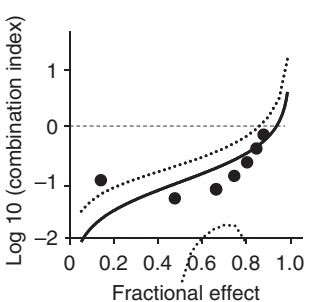

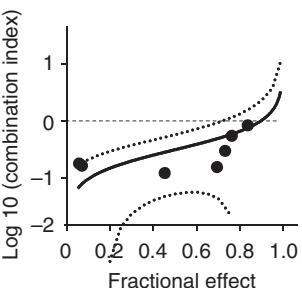

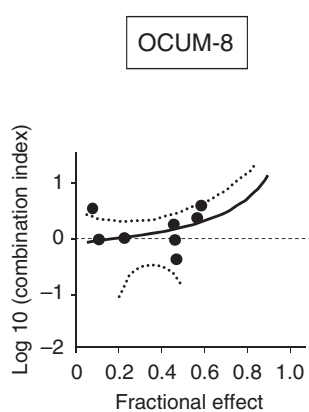

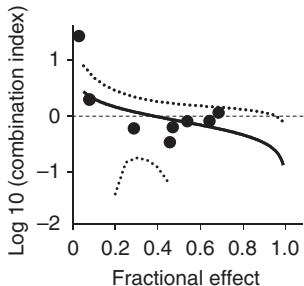

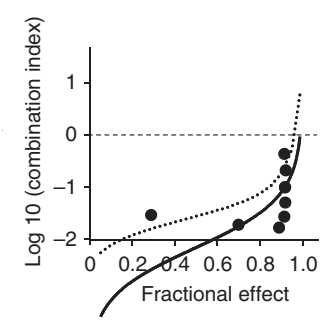

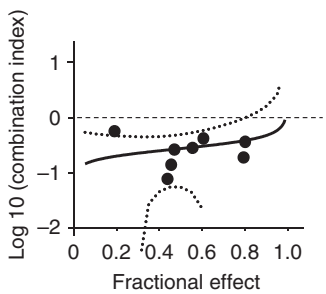

Figure 2 Synergistic effect of gefitinib or lapatinib with SN38 in gastric cancer cell lines. (A) The combination with gefitinib, and SN38 significantly suppressed cancer cell proliferation in OCUM-2M, OCUM-2M/SN38, and OCUM-8/SN3 cells in comparison to the SN38 alone, but not OCUM-8 cells. The expected value of the combined effects (\%) was defined as: effects of SN38 alone/control $\times$ effects of gefitinib alone/control $\times 100 \%$. The proliferation of SN38-resistant cells exposed to the combination of gefitinib plus SN38 was lower than expected. The results are presented as the mean of three independent experiments, and the bars indicate the s.d. $* P<0.05$ vs control. (B) The Cl plots derived from CalcuSyn software. The combination of gefitinib or lapatinib plus SN38 shows a synergistic (log $\mathrm{Cl}<0$ ) growth-inhibitory effect for OCUM-2M/SN38 and OCUM-8/SN38 cells, but antagonistic effect (log $\mathrm{Cl}>0)$ was found at some points in OCUM-2M and OCUM-8 cells. dotted line, log $(\mathrm{Cl})=0$. 
A



EGFR TRNA

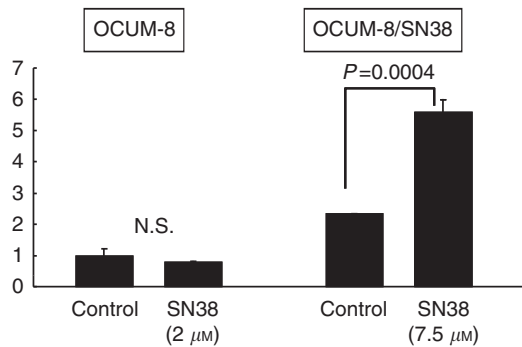

HER2 MRNA
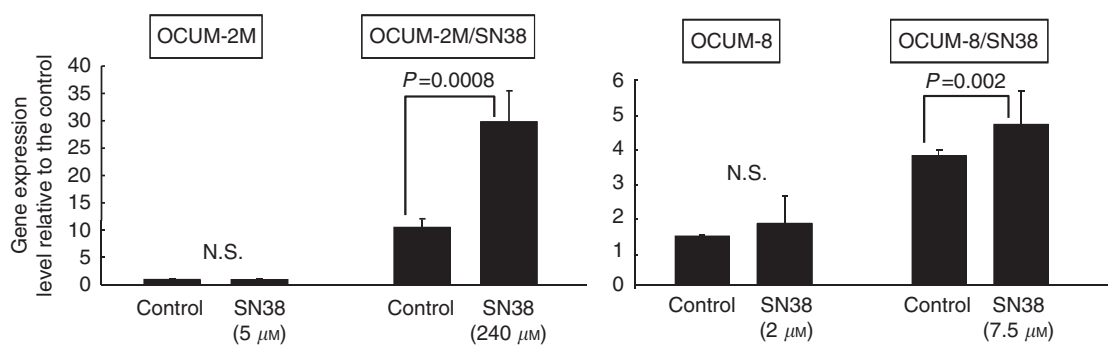

B
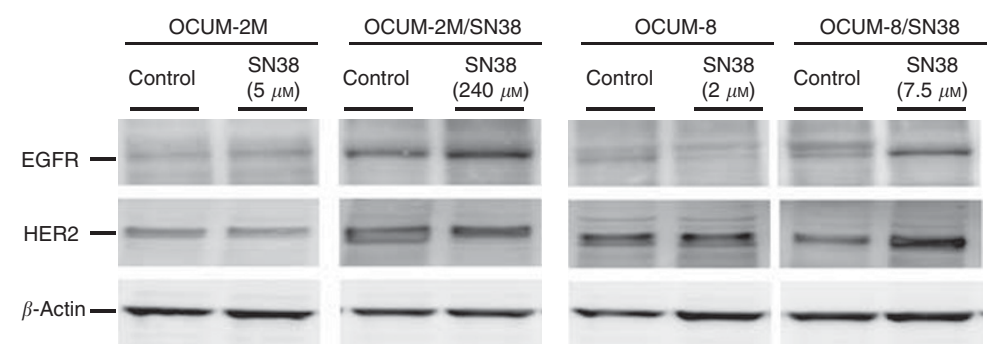

Figure 3 Effects of SN38 on the expression of HER family by reverse transcription-PCR. (A) SN38 increased the expression of EGFR and HER2 in OCUM-2M/SN38 and OCUM-8/SN38, but not in OCUM-2M and OCUM-8. (B) The expression of EGFR and HER2 was increased by SN38 in OCUM-2M/SN38 and OCUM-8/SN38 cells.

apoptosis by $\mathrm{SN} 38$ (at $\mathrm{IC}_{50}$ ) monotherapy between the parent cell lines and SN38-resistant cell lines. Taken together, lapatinib also significantly increased apoptosis rates in SN38-resistant cell lines (data not shown).

\section{Effects of SN38 plus an EGFR inhibitor on the expression} of apoptosis-related molecules

In OCUM-2M/SN38 and OCUM-8/SN38 cells, the mRNA expression levels of caspase-6, $p 53$, and $D A P K-2$ were significantly increased when cells were cultured in the presence of SN38 plus lapatinib $(200 \mathrm{~nm})$, compared with exposure to SN38 alone or lapatinib alone. In contrast, there were no significant differences in the expression levels of these genes between the SN38 monotherapy and the SN38 plus lapatinib treatment in either OCUM-2M or OCUM-8 cells (Figure 4B). The protein levels of caspase-6, p53, and DAPK-2 were increased in the presence of SN38 plus lapatinib, compared with exposure to $\mathrm{SN} 38$ alone or lapatinib alone, in OCUM-2M/SN38 and OCUM-8/SN38 cells (Figure 4C).

\section{Effects of EGFR inhibitors on the cell cycle}

The representative FACS analyses data were shown in Figure 5A. The percentage of cells in the S-phase was low in OCUM-2M/SN38 and OCUM-8/SN38 cells, in comparison with that in OCUM-2M and OCUM-8 cells. The EGFR inhibitor lapatinib increased the percentage of cells in the S-phase in OCUM-2M/SN38 and CUM-8/ SN38 cells, but not in OCUM-2M and OCUM-8 cells. Lapatinib decreased the percentage of cells in the G0/G1 in OCUM-2M/SN38 and CUM-8/SN38 cells (Figure 5B).

\section{Effects of EGFR inhibitors on SN38 metabolism-related genes, UGT1A1 and ABCG2}

The expression levels of ABCG2 and UGT1A1in OCUM-2M/SN38 and OCUM-8/SN38 cells were higher than those in the parent OCUM-2M and OCUM-8 cells. In OCUM-2M/SN38 and OCUM-8/ SN38 cells, the EGFR inhibitors gefitinib and lapatinib significantly decreased the mRNA expression levels of $A B C G 2$ and UGT1A1, in comparison with the vehicle control. In contrast, lapatinib increased the expression levels of $A B C G 2$ in OCUM-2M cells and OCUM-8 cells. Gefitinib increased the expression levels of UGT1A1 in OCUM-8 cells (Figure 5C). The protein levels of ABCG2 and UGT1A1in OCUM-2M/SN38 and OCUM-8/SN38 cells were higher than those in the parent OCUM-2M and OCUM- 8 cells, and was decreased by lapatinib in OCUM-2M/SN38 and OCUM-8/SN38 cells (Figure 5D).

\section{Effect of Lapatinib and/or SN38 on tumour development in vivo}

The mean volumes of the subcutaneous tumour of the control, Lapatinib, SN38, Lapatinib, plus SN38 groups were 101, 98, 96, and $60 \mathrm{~mm}^{2}$ at day 8 after administration, respectively. The size of the tumours in mice receiving the combination of SN38 with the Lapatinib was significantly $(P<0.01)$ smaller than in those 
A

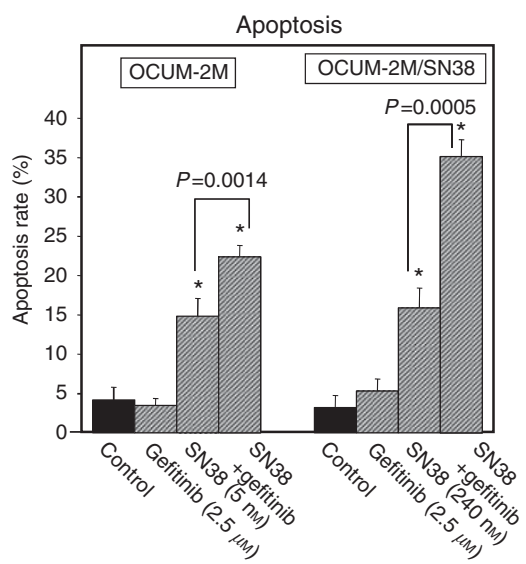

B
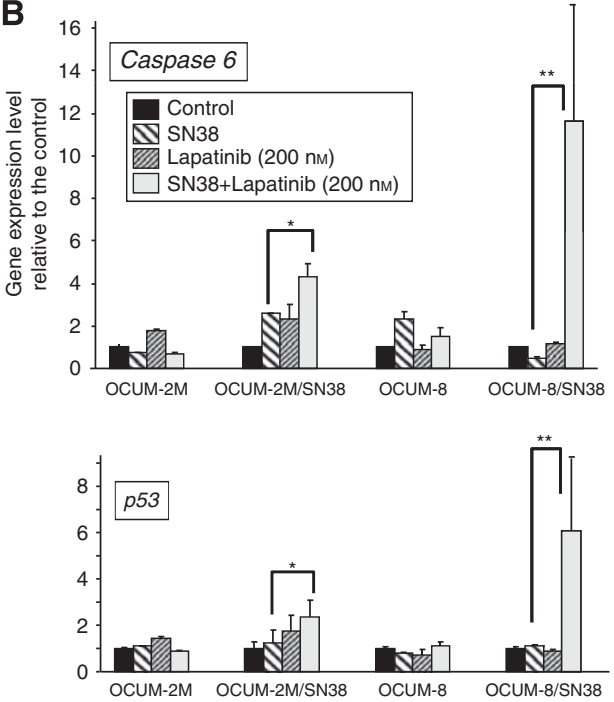

C
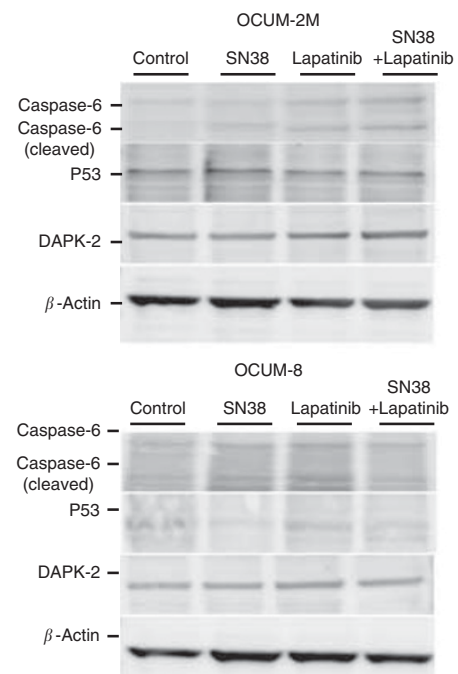
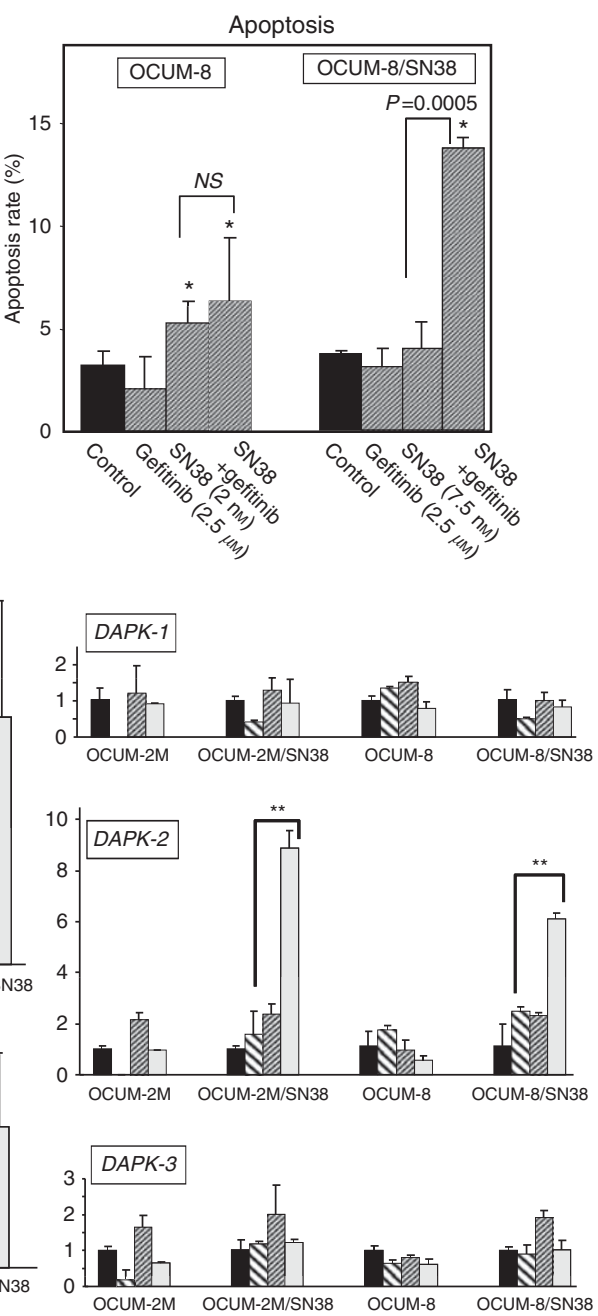

OCUM-2M/SN38


Figure 4 Apoptosis induction by gefitinib and/or SN38 in gastric cancer cells. (A) SN38 was added at the concentration of IC 50 . In all of the four cell lines tested, no significant difference of the apoptosis rate was found between gefitinib ( $2.5 \mu \mathrm{M})$ treatment and control. In contrast, the apoptosis rate induced by the combination of gefitinib and SN38 was significantly increased in comparison to the SN38 alone in the OCUM-2M, OCUM-2M/SN38, and OCUM-8/ SN38 cells. $* P<0.05$ vs control. (B) Lapatinib with SN38 significantly increased the mRNA expression levels of caspase-6, p53, and DAPK-2 compared with exposure to SN38 alone or lapatinib alone in SN38-resistant cells, OCUM-2M/SN38 and OCUM-8/SN38, but not in OCUM-2M and OCUM-8 cells. $* P<0.05$ vs control; *** $<0.0$ I vs control. (C) SN38 plus lapatinib increased caspase-6, p53, and DAPK-2 expression, compared with either alone, in SN38resistant cells. 
A

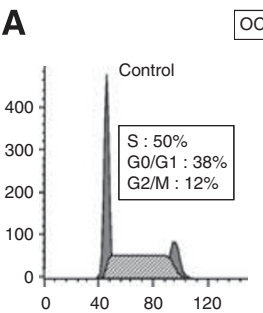

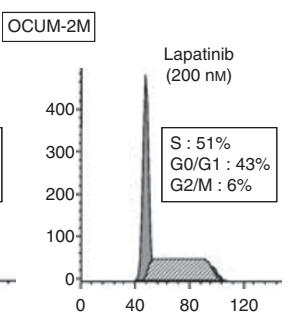

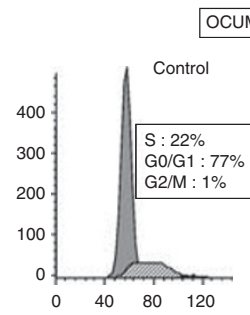

OCUM-2M/SN38

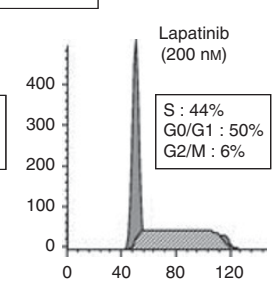

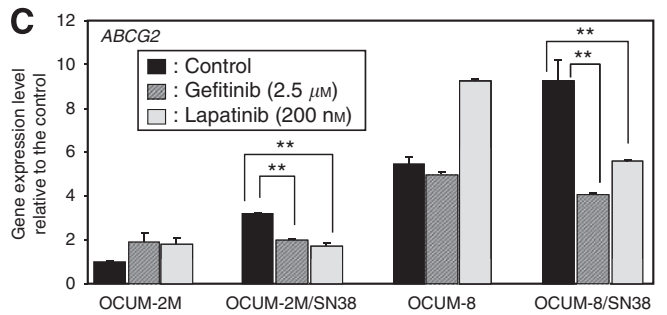
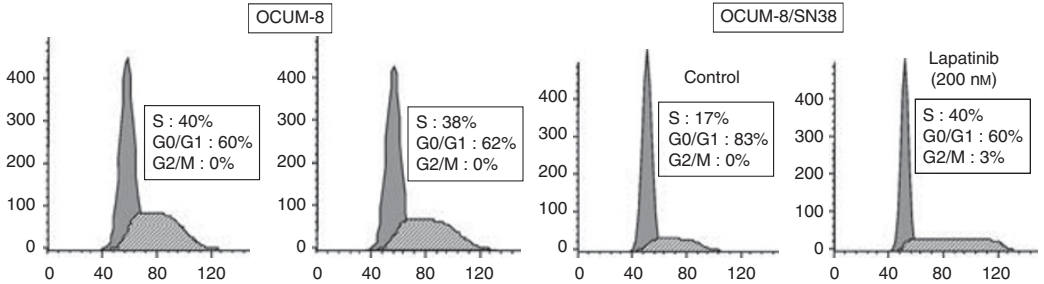

B
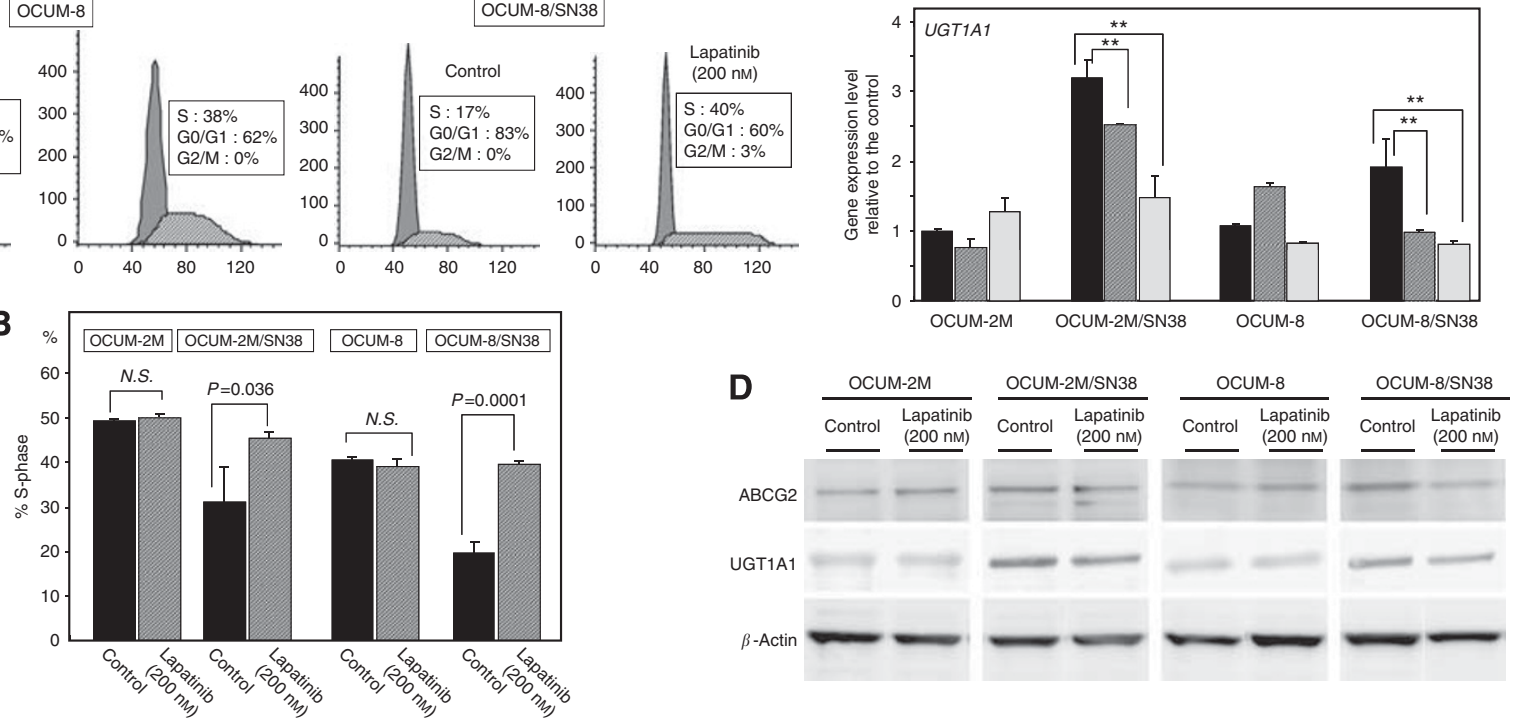

Figure 5 Effects of EGFR inhibitors on the cell cycle and SN38 metabolism-related genes. (A) The representative FACS-based cell-cycle analyses. (B) The percentage of cells in the S-phase in OCUM-2M/SN38 and OCUM-8/SN38 cells was significantly increased following the addiction of lapatinib (200 nM), compared with the control. N.S. = not significant. (C) EGFR inhibitor, lapatinib and gefitinib, significantly increased the mRNA expression levels of UGTIA I and ABCG2 in OCUM-2M/SN38 and OCUM-8/SN38 cells. In contrast, in OCUM-2M and OCUM-8 cells, the effect by EGFR inhibitors on the expression levels of UGTIAI and ABCG2 were not maintained the same. ${ }^{*} P<0.01$ vs control. (D) ABCG2 and UGTIAI expression in SN38-resistant cells were higher than those in the parent cells, and was decreased by lapatinib in SN38-resistant cells (D).

receiving either SN38 or Lapatinib alone. The significant difference of tumour size between SN38 alone and SN38 with the Lapatinib was found between day 8 and day 15 after administration. The tumour size by the combination of lapatinib and SN38 was lower than the expected value, evaluating that the combination of Lapatinib and SN38 shows a synergistic effect. In contrast, no significant difference of tumour size between control and Lapatinib was found (Figure 6).

\section{DISCUSSION}

The combination of an EGFR inhibitor, lapatinib or gefitinib, with SN38 achieved a greater suppression of cancer cell proliferation in all four cell lines tested than monotherapy with either agent alone. Previous studies have shown that lapatinib may be effective in combination with irinotecan as a chemotherapeutic treatment for chemonative gastrointestinal cancer cells (LaBonte et al, 2009). This is supported by our observation that the proliferation of parent gastric cancer cells was more highly decreased by the combination of an EGFR inhibitor and SN38 than by treatment with SN38 alone. Moreover, the combination of an EGFR inhibitor and SN38 synergistically suppressed cell growth and induced apoptosis in the SN38-resistant gastric cancer cell lines, OCUM$2 \mathrm{M} / \mathrm{SN} 38$ and OCUM-8/SN38, but not in OCUM-2M and OCUM-8 cells. Taken together, the in vivo tumour by OCUM-2M/SN38 cells was significantly decreased by SN38 plus Lapatinib compared with the size resulting from SN38 alone. These findings suggested that
EGFR inhibitors might be therapeutically promising for irinotecan-refractory gastric carcinomas when used in combination with SN38. Clinical studies have shown that the combination of irinotecan and the EGFR inhibitor cetuximab is preferable for patients with irinotecan-refractory colorectal cancer (Cunningham et al, 2004; Saltz et al, 2004; Vincenzi et al, 2006). In gastric cancer, EGFR has become the target of choice (Kim et al, 2008), while EGFR inhibitors have proven only weakly effective (Namiki et al, 2006; Becker et al, 2006b). Further clinical studies will be needed to determine whether EGFR inhibitors reverse the resistance to irinotecan in patients with advanced gastric cancer.

The present study indicated that SN38 upregulated the expression levels of EGFR and HER2 in SN38-resistant gastric cancer cells, but not parent cells. Increased EGFR/HER2 expression may be a survival response by some tumours exposed to chemotherapeutic agents. The activation of EGFR could have an important role for the cell proliferation and the inhibition of apoptosis (Kishida et al, 2005), indicating that the SN38-induced activation of the EGF/EGFR may be involved in the resistance of gastric cancer cells to irinotecan. SN38-resistant cancer cells might be more dependent on EGFR signalling pathways for survival, and therefore may become more sensitive to EGFR inhibitors. The different effects of SN38 treatment on EGFR expression might explain the different effects of the EGFR inhibitor plus SN38 combination treatment between the parent cells and resistant cells. Several studies have reported that tumour cell lines with acquired resistance to chemotherapeutic drugs can develop increased expression of EGFR (Dai et al, 2005; Kishida et al, 2005; Wang 


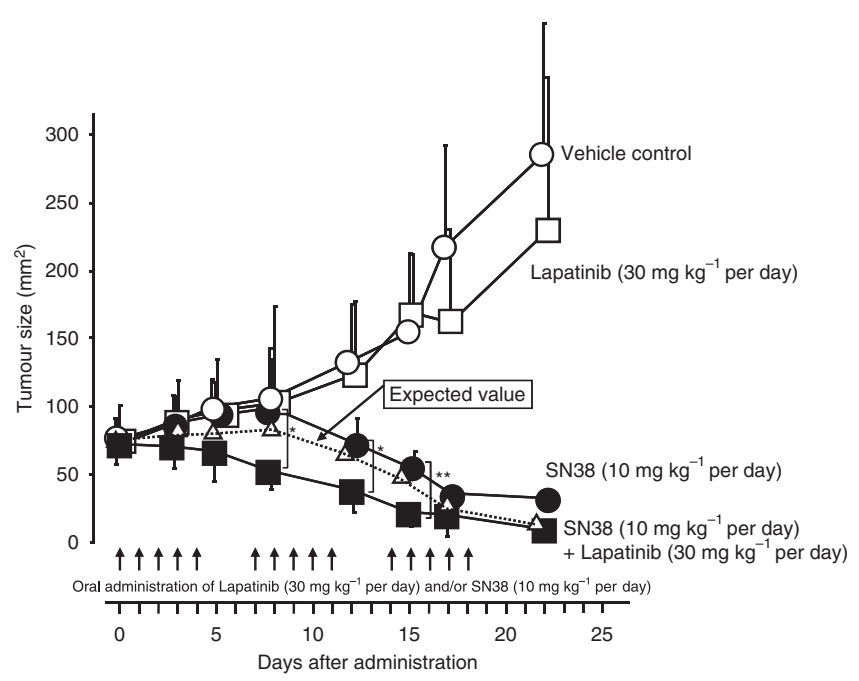

Figure 6 Effect of the combination of SN38 with Lapatinib on the proliferation of xenografted tumour in vivo. The tumour by OCUM-2M/ SN38 cells was significantly decreased by SN38 plus Lapatinib (ם) compared with the size resulting from SN38 alone treatment $(\mathbf{0})$. The significant difference of tumour size between SN38 alone and SN38 with the Lapatinib was found between day 8 and day 15 after administration. The tumour size by the combination of Lapatinib and SN38 was lower than the expected value $(\Delta)$ between day 8 and day 15 after administration. In contrast, no significant difference of tumour size between vehicle control $(O)$ and Lapatinib alone treatment $(\square)$ was found. $* P<0.05$; ** $P<0.01$. The expected value of the combined effects $=$ the effects of SN38 $\times$ the effects of lapatinib/vehicle control (dotted line).

et al, 2007). Kishida et al (2005) suggested that the mechanisms responsible for the SN38-induced activation of the EGFR might include the generation of reactive oxygen species and the activation of protein kinase $\mathrm{C}$, followed by metalloproteinase activation and the sequential ectodomain shedding of EGFR ligands. In addition, Wang et al (2007) suggested that the chemotherapy-induced EGFR activation is regulated by heparinbinding EGF-like growth factor (HB-EGF). These mechanisms might be associated with the upregulation of EGFR and HER2 in the SN38-resistant gastric cancer cell lines.

Gefitinib at a concentration of $2.5 \mu \mathrm{M}$ and lapatinib at $200 \mathrm{~nm}$ were used in each assay. In our previous study, different concentrations of gefitinib ranging from 0.1 to $4 \mu \mathrm{M}$, or lapatinib ranging from 50 to $400 \mathrm{~nm}$ have been applied, and the slight growth inhibiting ability of gefitinib was found at each concentration. Since $2.5 \mu \mathrm{m}$ gefitinib and $200 \mathrm{~nm}$ lapatinib showed no significant effect on the proliferation of gastric cancer cell lines, we used the concentration at each assay. Our study indicated that either EGFR inhibitor at low concentration suppressed the proliferation of cancer cells in combination with SN38. In contrast, the antagonistic effect $(\log \mathrm{CI}>0)$ was found at $>128 \mathrm{nM} \mathrm{SN38}$ and $16 \mathrm{nM}$ SN38 with the combination in the parent cell lines, OCUM-2M and OCUM-8, respectively, but not found in the resistant cell lines. Because the $\mathrm{IC}_{50}$ value of SN38 for OCUM-2M and OCUM-8 was 6.4 and $2.6 \mathrm{nM}$, respectively, the antagonism was shown only at high concentration of SN38 (more than five times of $\mathrm{IC}_{50}$ ). These findings might suggest that the combination of gefitinib or lapatinib might reduce the anti-tumour effects of SN38 at very high concentration of SN38, while these concentrations were not clinical practice. Although the toxicity of irinotecan or an EGFR inhibitor is predictable, dose adjustment should be made when necessary. The combination of EGFR inhibitor and SN38 at a low dose might reverse SN38 resistance, and could be useful for patients experiencing toxicity from SN38.
The combination of SN38 and an EGFR inhibitor significantly increased apoptosis rates in SN38-resistant cell lines, compared with SN38 alone. These findings suggested that the synergistic anti-proliferative effect of the EGFR inhibitors used in this study might be explained by an enhancement of apoptosis. Irinotecan causes S-phase-specific cell killing by poisoning topoisomerase I (Topo I) in the cells. In the present study, the percentage of cells in the S-phase was low in the SN38-resistant cell lines, and the EGFR inhibitors increased the percentage of cells in the S-phase in the SN38-resistant cell lines, but not in the parent cells. These findings suggested that upregulation of the S-phase in the SN38-resistant cell lines by the EGFR inhibitors might be one of the mechanisms responsible for the increase of apoptosis in the combination therapy with SN38.

Several studies have been done to uncover possible mechanisms for the cellular resistance to irinotecan. Dai et al (2008) reported that lapatinib reverses ABCB1- and ABCG2-mediated tumour multidrug resistance by directly inhibiting their transport function. Our study also showed that EGFR inhibitors significantly decreased ABCG2 levels in SN38-resistant cells, but not parent cells. Moreover, the expression level of UGT1A1, which catalyses the glucuronidation of $\mathrm{SN} 38$, was decreased by the combination treatment. The downregulation of SN38 metabolismrelated genes, ABCG2 and UGT1A1, by EGFR inhibitors may also be one of the mechanisms involved in the synergistic effects between the EGFR inhibitors and irinotecan in SN38resistant cells.

The combination of an EGFR inhibitor and SN38 upregulated the expression level of apoptosis-related molecules, caspase-6, p53, and DAPK-2, in both SN38-resistant cell lines. The caspase family comprises enzymes engaged in cell apoptosis (Korzeniewska-Dyl, 2008). Caspase-6 signalling induced by an EGFR inhibitor might contribute to the induction of apoptosis in SN38-resistant cancer cells. p53, a nuclear phosphoprotein, has an important role in apoptosis, growth arrest, genomic stability, cell senescence, and differentiation. In A549 cells, gefitinib induces apoptosis through a $p 53$-dependent upregulation of pro-apoptotic molecules and downregulation of anti-apoptotic molecules (Chang et al, 2008). In some non-small cell lung cancers without EGFR mutations, $p 53$ had a role in determining gefitinib sensitivity (Rho et al, 2007). In our study, p53 expression was only clearly increased in SN38-resistant cells. Epidermal growth factor receptor inhibitors regulated p53 signalling in SN38-resistant cell lines. The DAPK family is associated with apoptotic or autophagic cell death signals in response to various cellular stresses (Kogel et al, 2001; Gozuacik and Kimchi, 2006), and its members can induce apoptosis in a p53-dependent manner (Kogel et al, 2003). In our study, elevated expression of $D A P K-2$ was observed in both OCUM-2M/SN38 and OCUM-8/SN38 cells, while there were no changes in DAPK-1 or DAPK-3 expression. The upregulation of caspase-6, p53, and DAPK-2 might take part in the synergistic effect between the EGFR inhibitors and SN38, and might result in the synergistic induction of apoptosis of irinotecan-resistant gastric cancer cells.

Epidermal growth factor receptor inhibitors achieved a better clinical response rate for colorectal carcinomas when used in combination with cytostatic drugs, including irinotecan, 5-FU, and OXA (Yen et al, 2010; Folprecht et al, 2010). Our study found that the combination of an EGFR inhibitor with either 5-FU or OXA did not exhibit a synergistic effect, but the combination of an EGFR inhibitor with irinotecan did. The combination of an EGFR inhibitor with irinotecan might be more important for anti-cancer therapy than that with 5-FU or OXA. Caspase-6, p53, DAPK-2, ABCG2, and UGT1A1 might be useful surrogate markers to predict better clinical response by an EGFR inhibitor in combination with irinotecan.

In conclusion, EGFR inhibitors increased the sensitivity of SN38 in gastric cancer cells, especially in SN38-resistant gastric 
cancer cells. The mechanism of this synergism by EGFR inhibitors might be responsible for the upregulation of caspase- 6 , p53, and DAPK-2 and the downregulation of ABCG2 and UGT1A1 in SN38resistant gastric cancer cells, resulting in the induction of apoptosis of irinotecan-resistant cells. The combination treatment with an EGFR inhibitor and irinotecan might be a therapeutically promising approach for irinotecan-refractory gastric carcinomas.

\section{REFERENCES}

Arnold D, Peinert S, Voigt W, Schmoll HJ (2006) Epidermal growth factor receptor tyrosine kinase inhibitors: present and future role in gastrointestinal cancer treatment: a review. Oncologist 11: 602-611

Becker JC, Muller-Tidow C, Serve H, Domschke W, Pohle T (2006a) Role of receptor tyrosine kinases in gastric cancer: new targets for a selective therapy. World J Gastroenterol 12: $3297-3305$

Becker JC, Muller-Tidow C, Stolte M, Fujimori T, Tidow N, Ilea AM, Brandts C, Tickenbrock L, Serve H, Berdel WE, Domschke W, Pohle T (2006b) Acetylsalicylic acid enhances antiproliferative effects of the EGFR inhibitor gefitinib in the absence of activating mutations in gastric cancer. Int J Oncol 29: 615-623

Bugat R (2003) Irinotecan in the treatment of gastric cancer. Ann Oncol 14(Suppl 2): ii37 - ii40

Chang GC, Yu CT, Tsai CH, Tsai JR, Chen JC, Wu CC, Wu WJ, Hsu SL (2008) An epidermal growth factor inhibitor, Gefitinib, induces apoptosis through a p53-dependent upregulation of pro-apoptotic molecules and downregulation of anti-apoptotic molecules in human lung adenocarcinoma A549 cells. Eur J Pharmacol 600: 37 - 44

Chou TC, Talalay P (1984) Quantitative analysis of dose-effect relationships: the combined effects of multiple drugs or enzyme inhibitors. Adv Enzyme Regul 22: $27-55$

Ciardiello F, Tortora G (2001) A novel approach in the treatment of cancer: targeting the epidermal growth factor receptor. Clin Cancer Res 7: $2958-2970$

Cunningham D, Humblet Y, Siena S, Khayat D, Bleiberg H, Santoro A, Bets D, Mueser M, Harstrick A, Verslype C, Chau I, Van Cutsem E (2004) Cetuximab monotherapy and cetuximab plus irinotecan in irinotecanrefractory metastatic colorectal cancer. $N$ Engl J Med 351: $337-345$

Dai CL, Tiwari AK, Wu CP, Su XD, Wang SR, Liu DG, Ashby Jr CR, Huang Y, Robey RW, Liang YJ, Chen LM, Shi CJ, Ambudkar SV, Chen ZS, Fu LW (2008) Lapatinib (Tykerb, GW572016) reverses multidrug resistance in cancer cells by inhibiting the activity of ATP-binding cassette subfamily B member 1 and G member 2. Cancer Res 68: $7905-7914$

Dai Q, Ling YH, Lia M, Zou YY, Kroog G, Iwata KK, Perez-Soler R (2005) Enhanced sensitivity to the HER1/epidermal growth factor receptor tyrosine kinase inhibitor erlotinib hydrochloride in chemotherapyresistant tumor cell lines. Clin Cancer Res 11: 1572-1578

Farhat FS (2007) A general review of the role of irinotecan (CPT11) in the treatment of gastric cancer. Med Oncol 24: 137-146

Folprecht G, Gruenberger T, Bechstein WO, Raab HR, Lordick F, Hartmann JT, Lang H, Frilling A, Stoehlmacher J, Weitz J, Konopke R, Stroszczynski C, Liersch T, Ockert D, Herrmann T, Goekkurt E, Parisi F, Kohne CH (2010) Tumour response and secondary resectability of colorectal liver metastases following neoadjuvant chemotherapy with cetuximab: the CELIM randomised phase 2 trial. Lancet Oncol 11: $38-47$

Galizia G, Lieto E, Orditura M, Castellano P, Mura AL, Imperatore V, Pinto M, Zamboli A, De Vita F, Ferraraccio F (2007) Epidermal growth factor receptor (EGFR) expression is associated with a worse prognosis in gastric cancer patients undergoing curative surgery. World J Surg 31: $1458-1468$

Gozuacik D, Kimchi A (2006) DAPk protein family and cancer. Autophagy 2: $74-79$

Kim MA, Lee HS, Lee HE, Jeon YK, Yang HK, Kim WH (2008) EGFR in gastric carcinomas: prognostic significance of protein overexpression and high gene copy number. Histopathology 52: 738-746

Kishida O, Miyazaki Y, Murayama Y, Ogasa M, Miyazaki T, Yamamoto T, Watabe K, Tsutsui S, Kiyohara T, Shimomura I, Shinomura Y (2005) Gefitinib ('Iressa', ZD1839) inhibits SN38-triggered EGF signals and IL-8 production in gastric cancer cells. Cancer Chemother Pharmacol 55: $393-403$

\section{ACKNOWLEDGEMENTS}

We thank Masako Shinkawa (Osaka City University Graduate School of Medicine) for technical advice on RT - PCR analysis. This study is partially founded by Japan-China Sasagawa Medical Scholarship, by Foundation for Promotion of Cancer Research, and by KAKENHI (Grant-in-Aid for Scientific Research, Nos. 20591573, 22390262, and 23390329).

Knight LA, Di Nicolantonio F, Whitehouse P, Mercer S, Sharma S, Glaysher S, Johnson P, Cree IA (2004) The in vitro effect of gefitinib ('Iressa') alone and in combination with cytotoxic chemotherapy on human solid tumours. BMC Cancer 4: 83

Kogel D, Prehn JH, Scheidtmann KH (2001) The DAP kinase family of pro-apoptotic proteins: novel players in the apoptotic game. Bioessays 23: $352-358$

Kogel D, Reimertz C, Dussmann H, Mech P, Scheidtmann KH, Prehn JH (2003) The death associated protein (DAP) kinase homologue Dlk/ZIP kinase induces p19ARF- and p53-independent apoptosis. Eur J Cancer 39: $249-256$

Korzeniewska-Dyl I (2008) Caspases-a new target in inflammation and cancer therapy?. Pol Merkur Lekarski 24: 5-7

LaBonte MJ, Manegold PC, Wilson PM, Fazzone W, Louie SG, Lenz HJ, Ladner RD (2009) The dual EGFR/HER-2 tyrosine kinase inhibitor lapatinib sensitizes colon and gastric cancer cells to the irinotecan active metabolite SN-38. Int J Cancer 125: $2957-2969$

Liakakos T, Xeropotamos N, Ziogas D, Roukos D (2008) EGFR as a prognostic marker for gastric cancer. World J Surg 32: 1225-1226; author reply $1227-1229$

Marth C, Daxenbichler G, Dapunt O (1986) Synergistic antiproliferative effect of human recombinant interferons and retinoic acid in cultured breast cancer cells. J Natl Cancer Inst 77: 1197-1202

Namiki Y, Namiki T, Yoshida H, Date M, Yashiro M, Matsumoto K, Nakamura T, Yanagihara K, Tada N, Satoi J, Fujise K (2006) Preclinical study of a 'tailor-made' combination of NK4-expressing gene therapy and gefitinib (ZD1839, Iressa) for disseminated peritoneal scirrhous gastric cancer. Int J Cancer 118: 1545 - 1555

Network NCC (1998) NCCN practice guidelines for upper gastrointestinal carcinomas. National Comprehensive Cancer Network. Oncology (Williston Park) 12: 179-223

Nicholson RI, Gee JM, Harper ME (2001) EGFR and cancer prognosis. Eur J Cancer 37(Suppl 4): S9-15

Pfaffl MW (2001) A new mathematical model for relative quantification in real-time RT-PCR. Nucleic Acids Res 29: e45

Pommier Y, Pourquier P, Fan Y, Strumberg D (1998) Mechanism of action of eukaryotic DNA topoisomerase I and drugs targeted to the enzyme. Biochim Biophys Acta 1400: $83-105$

Rho JK, Choi YJ, Ryoo BY, Na II, Yang SH, Kim CH, Lee JC (2007) p53 enhances gefitinib-induced growth inhibition and apoptosis by regulation of Fas in non-small cell lung cancer. Cancer Res 67: $1163-1169$

Rojo F, Tabernero J, Albanell J, Van Cutsem E, Ohtsu A, Doi T, Koizumi W, Shirao K, Takiuchi H, Ramon y Cajal S, Baselga J (2006) Pharmacodynamic studies of gefitinib in tumor biopsy specimens from patients with advanced gastric carcinoma. J Clin Oncol 24: 4309-4316

Saltz LB, Meropol NJ, Loehrer Sr PJ, Needle MN, Kopit J, Mayer RJ (2004) Phase II trial of cetuximab in patients with refractory colorectal cancer that expresses the epidermal growth factor receptor. J Clin Oncol 22: $1201-1208$

Segal NH, Saltz LB (2009) Evolving treatment of advanced colon cancer. Annu Rev Med 60: 207-219

Takemura S, Yashiro M, Sunami T, Tendo M, Hirakawa K (2004) Novel models for human scirrhous gastric carcinoma in vivo. Cancer Sci 95: $893-900$

Vincenzi B, Santini D, Rabitti C, Coppola R, Beomonte Zobel B, Trodella L, Tonini G (2006) Cetuximab and irinotecan as third-line therapy in advanced colorectal cancer patients: a single centre phase II trial. Br J Cancer 94: 792 - 797

Wang F, Liu R, Lee SW, Sloss CM, Couget J, Cusack JC (2007) Heparin-binding EGF-like growth factor is an early response gene to 
chemotherapy and contributes to chemotherapy resistance. Oncogene 26 2006-2016

Xu Y, Villalona-Calero MA (2002) Irinotecan: mechanisms of tumor resistance and novel strategies for modulating its activity. Ann Oncol 13: $1841-1851$

Yashiro M, Chung YS, Nishimura S, Inoue T, Sowa M (1995) Establishment of two new scirrhous gastric cancer cell lines: analysis of factors associated with disseminated metastasis. $\mathrm{Br}$ J Cancer 72: $1200-1210$

Yen LC, Uen YH, Wu DC, Lu CY, Yu FJ, Wu IC, Lin SR, Wang JY (2010) Activating KRAS mutations and overexpression of epidermal growth factor receptor as independent predictors in metastatic colorectal cancer patients treated with cetuximab. Ann Surg 251: 254-260

Yokoyama H, Ikehara Y, Kodera Y, Ikehara S, Yatabe Y, Mochizuki Y,

Koike M, Fujiwara M, Nakao A, Tatematsu M, Nakanishi H (2006)

Molecular basis for sensitivity and acquired resistance to gefitinib in

HER2-overexpressing human gastric cancer cell lines derived from liver metastasis. Br J Cancer 95: 1504-1513

Zhang X, Yashiro M, Qiu H, Nishii T, Matsuzaki T, Hirakawa K (2010) Establishment and characterization of multidrug-resistant gastric cancer cell lines. Anticancer Res 30: 915-921

This work is published under the standard license to publish agreement. After 12 months the work will become freely available and the license terms will switch to a Creative Commons Attribution-NonCommercial-Share Alike 3.0 Unported License. 